\title{
EDUCAÇÃO AMBIENTAL NO ENSINO SUPERIOR BRASILEIRO: ANÁLISE DO EXAME NACIONAL DE DESEMPENHO DOS ESTUDANTES (ENADE) APLICADO AOS CURSOS DE DIREITO (2006-2015)
}

\author{
Alboni Marisa Dudeque Pianovski Vieira ${ }^{1}$ \\ Adrielly Pinho dos Santos ${ }^{2}$ \\ Mariana Gmach Philippi ${ }^{3}$
}

Resumo: $O$ artigo propõe-se a avaliar se os conceitos e competências relacionados à Educação Ambiental estão inseridos no ensino superior nacional, especificamente no que tange ao curso de Direito, e se os princípios e objetivos previstos na Política Nacional de Educação Ambiental são, em alguma medida, contemplados nos exames aplicados aos estudantes. Os objetivos específicos elencados foram: averiguar se e como as questões ambientais são abordadas no ensino superior; e apurar em que medida este conteúdo é avaliado no Enade. Com arcabouço bibliográfico e documental a pesquisa analisou os dados do Exame Nacional de Desempenho dos Estudantes (ENADE), aplicados no período trienal entre 2006 e 2015, aos cursos do Direito do Brasil.

Palavras-chave: ENADE; Educação Ambiental; Ensino Superior.

1Pontifícia Universidade Católica do Paraná. E-mail: alboni@alboni.com

2Pontifícia Universidade Católica do Paraná. E-mail: adrielly_pinho@hotmail.com

3Pontifícia Universidade Católica do Paraná. E-mail: mariana.philippi@hotmail.com 


\section{Introdução}

A introdução da Educação Ambiental no ensino superior brasileiro é um tema relativamente recente, que comporta amplo debate, seja no que tange às formas de inserção dessas questões nas matrizes curriculares das universidades, seja quanto ao grau de eficácia com o qual elas são trabalhadas e se elas viabilizam, de fato, alguma transformação social significativa.

Desde que emergiu no contexto internacional, em meados da década de 1960, a Educação Ambiental propunha-se a tornar-se um mecanismo de educação cidadã, tendo por objetivo o enfrentamento dos problemas ambientais e pautando-se, sobretudo, no direito ao acesso à informação e na assistência primordial às camadas mais vulneráveis da população. Nesse contexto, o Programa Internacional de Educação Ambiental destinou-se a instituir uma nova ética global, atenta às questões climáticas e ambientais que passavam a ganhar destaque em debates ao redor do mundo.

Nacionalmente, em resposta aos debates e indicativos internacionais a respeito do tema, a Política Nacional de Educação Ambiental fora instituída pela Lei n. 9.099, de 1995, que determina e orienta, em conjunto com o Decreto regulamentar n. 4.285/2002 e, principalmente, em consonância com o artigo 225, inciso $\mathrm{VI}$, da Constituição Federal, o desenvolvimento de ações educativas, pautadas nas premissas da articulação multidisciplinar e transversal, bem como da percepção integrada do meio ambiente, tanto no âmbito da educação formal como não formal. Busca-se viabilizar processos educativos transformadores, diretamente atrelados à realidade social e à efetiva compreensão dos problemas que provocam e que advêm da crise ambiental vivenciada em todo o mundo.

Sabe-se que, no âmbito do ensino formal, a Educação Ambiental deve permear, de forma transversal, todos os currículos, em todos os níveis de ensino. Porém, em que pese a instituição da Política Nacional de Educação Ambiental, repleta de princípios, objetivos e diretrizes para a implementação do ensino ambiental no Brasil, algumas questões permanecem latentes, especialmente, no contexto da efetividade normativa.

Questiona-se: a Educação Ambiental, nos cursos de Direito, é implementada de acordo com as normativas oriundas da Política Nacional e Internacional?

Nesse viés, a fim de buscar averiguar a implementação da Educação Ambiental no Ensino Superior, o artigo propõe-se a analisar os dados do Exame Nacional de Desempenho dos Estudantes (ENADE), aplicados no período trienal entre 2006 e 2015, aos cursos do Direito do Brasil, quais sejam, cursos que possuem o dever de preparar os estudantes para o enfrentamento de questões sociais, a exemplo da problemática ambiental, cujos impactos repercutem juridicamente perante à sociedade.

O foco da análise é avaliar se os conceitos e competências relacionados

à Educação Ambiental estão inseridos no ensino superior nacional, 
especificamente no que tange ao curso de Direito, e se os princípios e objetivos previstos na Política Nacional de Educação Ambiental são, em alguma medida, contemplados nos exames aplicados aos estudantes.

O estudo não tem por pretensão determinar o grau de eficácia da Política Nacional de Educação Ambiental na realidade brasileira, mas, sim, averiguar se e como as questões ambientais são abordadas no ensino superior e em que medida este conteúdo é avaliado no Enade, com vistas a contribuir para as pesquisas existentes no campo da Educação Ambiental nacional.

\section{Política Internacional de Educação Ambiental}

A análise dos aspectos práticos da Educação Ambiental no contexto do ensino superior, no Brasil, demanda, em um primeiro momento, a compreensão de como essa temática surgiu e desenvolveu-se no cenário global, para então adentrar nos diplomas normativos brasileiros.

O primeiro movimento formal de escala internacional orientado especificamente à questão da Educação Ambiental remonta ao ano de 1968, com a Criação do Conselho para Educação Ambiental, no Reino Unido (MINISTÉRIO DA EDUCAÇÃO, 2018b). Ainda que mereça destaque pelo pioneirismo, o Conselho não culminou diretamente na criação das bases sobre as quais se desenvolveria a Política Nacional de Educação Ambiental.

$\mathrm{Na}$ mesma esteira do que se observa com a tutela do meio ambiente de modo geral, foi a Conferência de Estocolmo, ocorrida no ano de 1972, evento de importância ímpar, no qual, entre outros temas sensíveis ao meio ambiente, colocou-se em foco a importância de Educação Ambiental transformadora como meio de combate e crítica aos problemas ambientais (DIAS, 2000) dos quais a comunidade internacional começava a se dar conta. Merece destaque, a esse respeito, o Princípio 19 da Declaração de Estocolmo, que assim dispõe:

Princípio 19: É indispensável um esforço para a educação em questões ambientais, dirigida tanto às gerações jovens como aos adultos e que preste a devida atenção ao setor da população menos privilegiado, para fundamentar as bases de uma opinião pública bem informada, e de uma conduta dos indivíduos, das empresas e das coletividades inspirada no sentido de sua responsabilidade sobre a proteção e melhoramento do meio ambiente em toda sua dimensão humana. É igualmente essencial que os meios de comunicação de massas evitem contribuir para a deterioração do meio ambiente humano e, ao contrário, difundam informação de caráter educativo sobre a necessidade de protegê-lo e melhorá-lo, a fim de que o homem possa desenvolver-se em todos os aspectos.

Foi nesse contexto que as bases para o Programa Internacional de Educação Ambiental começaram a ser moldadas, enquanto mecanismo de 
educação do cidadão para os problemas ambientais (UNESCO, 2017), pautadas no direito à informação e na assistência primordial às camadas mais vulneráveis da população.

Dando continuidade à onda de iniciativas orientadas à proteção do meio ambiente, desencadeadas pela Conferência de Estocolmo, e em resposta às recomendações dali resultantes, a Organização das Nações Unidas para a Educação, a Ciência e a Cultura (UNESCO) promoveu, em 1975, o primeiro Encontro Internacional em Educação Ambiental, sediado em Belgrado, na lugoslávia. O evento culminou na elaboração da Carta de Belgrado, que propunha a discussão de temas relacionados à fome, ao analfabetismo, à poluição, à exploração e à dominação, indicando que todos eles deveriam ser tratados de forma conjunta (MINISTÉRIO DO MEIO AMBIENTE, 1975).

No Encontro, discutiu-se ainda a necessidade de desenvolver programas de Educação Ambiental (EA), de abrangência regional e internacional. Nesse passo, "[...] a Carta de Belgrado define a estrutura e os princípios básicos da Educação Ambiental, identificando o crescimento econômico com controle ambiental como o conteúdo da nova ética global" (TOZONI-REIS, 2002). O documento propunha que o Programa Internacional de Educação Ambiental fosse dirigido tanto à educação formal quanto à informal, consistindo em um processo contínuo, permanente e multidisciplinar de educação, orientado principalmente às crianças e aos jovens.

Outra consequência direta do primeiro Encontro Internacional em Educação Ambiental foi a criação do Programa Internacional de Educação Ambiental (PIEA), instituído sobre o princípio da Educação Ambiental continuada, multidisciplinar e integrada às diferenças regionais e nacionais.

Em cumprimento à primeira fase do Programa Internacional de Educação Ambiental, a Unesco realizou, no ano de 1977, a Conferência Intergovernamental de Educação Ambiental de Tbilisi, na qual foram definidos os objetivos e as estratégias do Programa de Educação Ambiental, em nível nacional e internacional. Expõem-se as principais definições geradas pela Conferência, no que tange à estruturação internacional da Educação Ambiental:

Os objetivos da Educação Ambiental são definidos como consciência, conhecimentos, comportamento, aptidões e participação. Encontramos também estruturas formais e não formais da Educação Ambiental [...]. As preocupações pedagógicas aqui expressas valorizam o contato direto do educando com os elementos da natureza, os processos cognitivos de solução dos problemas ambientais, os materiais de ensino e os conteúdos e métodos interdisciplinares; a interdisciplinaridade aparece como uma prática pedagógica que tem por base as ciências naturais e sociais. A reorientação dos sistemas educacionais, a necessidade de divulgação dos conhecimentos e experiências ambientais positivas e a ênfase no papel dos meios de comunicação são estratégias gerais da 
Educação Ambiental expressas no documento (TOZONI-REIS, 2002).

Assim, o Programa Internacional de Educação Ambiental estruturou-se sobre as premissas da articulação multidisciplinar e da percepção integrada do meio ambiente, com vistas a fundamentar ações críticas e racionais capazes de responder às necessidades sociais. Para tanto, impunha-se, desde logo, que os processos educativos guardassem vinculação com a realidade, a fim de permitir uma compreensão adequada dos problemas ambientais (UNESCO, 1977). Ademais, a interdisciplinaridade deveria ser aplicada de modo a aproveitar e potencializar os benefícios específicos de cada disciplina, para permitir uma perspectiva global e equilibrada (UNESCO, 1977), inserindo-se a Educação Ambiental não mais como uma disciplina específica e apartada, mas como tema a ser abordado em cada área de conhecimento.

Já em 1987, na cidade de Moscou, o Congresso Internacional sobre Educação e Formação Relativas ao Meio Ambiente, que teve por finalidade avaliar as principais conquistas e obstáculos na implementação do Programa Internacional de Educação Ambiental desde a Conferência Intergovernamental de Tbilisi , deu origem a um conjunto de estratégias internacionais que ressaltavam "[...] a importância da formação de recursos humanos nas áreas formais e não formais da EA e na inclusão da dimensão ambiental nos currículos de todos os níveis" (PHILIPPI JUNIOR, 2014, p. 5).

A II Conferência das Nações Unidas sobre Meio Ambiente e Desenvolvimento, realizada no Rio de Janeiro em 1992 - Rio 92 -, culminou na criação da Agenda 21, que acabou por retomar algumas das questões definidas na Conferência Intergovernamental de Tbilisi. A Agenda previa, em seu capítulo 36, a necessidade de reestruturação do ensino formal, para abranger temas relativos ao desenvolvimento sustentável e viabilizar a capacidade de compreensão dos alunos no que tange às questões de meio ambiente e desenvolvimento (MINISTÉRIO DA EDUCAÇÃO; SECRETARIA DE EDUCAÇÃO FUNDAMENTAL, 2018).

No mesmo sentido, o Tratado de Educação Ambiental para as Sociedades Sustentáveis, outro fruto da Rio 92, concebia a Educação Ambiental como um processo dinâmico e constante, orientado a viabilizar a reflexão e o debate, constituindo verdadeira ferramenta de autotransformação da sociedade.

Em termos práticos, portanto, a implementação do Programa Internacional de Educação Ambiental e das demais diretrizes internacionais relativas à EA impuseram uma revisão crítica dos padrões de ensino tradicionais, muitas vezes apartados da realidade social e fragmentados em disciplinas pouco convergentes. Nacionalmente, porém, a revisão desses padrões representou e continua representando um desafio a ser enfrentado. 


\section{Política Nacional da Educação Ambiental}

A Educação Ambiental no Brasil é fruto de discussões, ações e resultados dos diversos movimentos internacionais em prol do meio ambiente, quando ocorre o despertar global para a necessidade de conscientização da população para a degradação ambiental.

É verdade que os movimentos internacionais em prol da implementação de uma Educação Ambiental formal e informal chamaram a atenção da "[...] sociedade brasileira para problemas que ela já vivenciava internamente, mas 0 formato que essa questão assumiu aqui refletiu as particularidades de nossa história e de nossa cultura"( LIMA, 2015, p. 35), isto porque, "[...] a educação reflete a sociedade na qual se desenvolve, tentando dar respostas aos desafios específicos e representando as visões de mundo que emergem em cada período histórico, tanto para a reprodução como para a transformação social" (LUZZI, 2012, p. 22).

Alguns fatores, porém, dificultaram a emergência dos aspectos ambientais na política brasileira, mormente porque diversos outros problemas clamavam pela atenção social. Em um primeiro momento, as questões sociais, como a desigualdade e a injustiça social, eram vistas como contrapostas aos problemas ambientais. A "[...] questão ambiental era rejeitada como uma ideologia importada, que representava uma alienação de nossos 'verdadeiros' problemas" (LIMA, 2015, p. 36).

A defesa do meio ambiente era vista também como um óbice ao crescimento econômico da nação. Na Conferência das Nações Unidas, em 1972, realizada em Estocolmo, o Brasil foi um dos países líderes da oposição à ideia de desenvolvimento sustentável. Acreditava-se que os problemas sociais internos seriam resolvidos a partir do crescimento econômico e por isso não se poderiam impor limites à industrialização, em prol do ambiente (LIMA, 2015, p. 38).

Menciona-se também o cenário político vivido pelo Brasil na época da ditadura, com privação absoluta das liberdades individuais do indivíduo, o que prejudicou a percepção dos problemas ambientais que assolavam todas as sociedades. Além disso, contribuíram para a ausência de consciência ambiental: "[...] a reduzida extensão relativa da classe média no conjunto da estrutura social brasileira; os baixos níveis de escolaridade e de informação sobre a temática ambiental da população; as concepções naturalistas de meio ambiente e os limitados níveis de educação política e cidadã" (LIMA, 2015, p. 38-39).

Diz-se, então, que "[...] o verdadeiro sentido da Educação Ambiental enquanto processo político, até então confundida com Ecologia, começou a tomar vulto na década de 1980" (PHILIPPI JUNIOR, 2014, p. 5) após a ditadura militar , especialmente, com a instituição da Política Nacional do Meio Ambiente (PNMA), por meio da Lei n. 6.938/1981, que positivou, dentre seus princípios, a Educação Ambiental a todos os níveis de ensino, inclusive a educação da 
comunidade, objetivando capacitá-la para a participação na defesa do meio ambiente (BRASIL, 2018) ${ }^{4}$.

Com a advento da Constituição Federal, em 1988, a Educação Ambiental, enquanto instrumento jurídico para preservação de direitos, assume natureza de direito fundamental, por força do artigo 225, inciso $\mathrm{VI}$, à medida que é imposto ao Poder Público a promoção da "[...] Educação Ambiental em todos os níveis de ensino e a conscientização pública para a preservação do meio ambiente" (BRASIL, 1988).

Mais de uma década depois, visando dar efetividade ao mandamento constitucional, a Lei n. 9.795, promulgada em 27 de abril de 1999 (BRASIL, 1999), insere no ordenamento jurídico brasileiro a Política Nacional de Educação Ambiental (PNEA) - artigo 6으, regulamentada pelo Decreto $n$. 4.281/2002 (BRASIL, 2002).

A PNEA deve ser implementada por órgãos e entidades integrantes do Sistema Nacional de Meio Ambiente, instituições educacionais públicas e privadas dos sistemas de ensino, órgãos públicos da União, dos Estados, do Distrito Federal e dos Municípios, e organizações não governamentais com atuação em Educação Ambiental (BRASIL, 2018).

A Educação Ambiental é definida no artigo 1을 da PNEA, como "[...] processos por meio dos quais o indivíduo e a coletividade constroem valores sociais, conhecimentos, habilidades, atitudes e competências voltadas para a conservação do meio ambiente" e, é considerada, na forma do artigo $2^{\circ}$, como "[...] componente essencial e permanente da educação nacional, devendo estar presente, de forma articulada, em todos os níveis e modalidades de ensino, seja no âmbito formal ou informal'.

Sendo um dever de todos os agentes sociais e políticos - Poder Público, instituições educativas, órgãos integrantes do Sistema Nacional do Meio Ambiente (SISNAMA), meios de comunicação de massa, empresas, entidades de classe, instituições públicas e privadas e a sociedade como um todo (BRASIL, 2018) - a EA deve ser desenvolvida, tanto no âmbito do ensino formal como informal, por meio da capacitação de recursos humanos, do desenvolvimento de estudos, pesquisas e experimentações, da produção e divulgação de material educativo e do acompanhamento e avaliação (BRASIL, 2018).

O desenvolvimento da EA deve se dar em observância aos princípios e objetivos estabelecidos na PNEA. Citam-se os princípios, previstos pelo artigo 4ํ: o enfoque humanista, holístico, democrático e participativo; a concepção do meio ambiente em sua totalidade, considerando a interdependência entre 0 meio natural, o socioeconômico e o cultural, sob o enfoque da sustentabilidade; o pluralismo de ideias e concepções pedagógicas, na perspectiva da inter, multi

4 Artigo 2º, inciso X. BRASIL. Lei n. 6.938 de 31 de agosto de 1981. Diário Oficial, Brasília, 1981. Disponível em: <http://www.planalto.gov.br/ccivil 03/leis/L6938.htm>. Acesso em: 18 jan. 2018. 
e transdisciplinaridade; a vinculação entre a ética, a educação, o trabalho e as práticas sociais; a garantia de continuidade e permanência do processo educativo; a permanente avaliação crítica do processo educativo; a abordagem articulada das questões ambientais locais, regionais, nacionais e globais e o reconhecimento e o respeito à pluralidade e à diversidade individual e cultural (BRASIL, 2018).

No mesmo sentido, os objetivos das ações de Educação Ambiental são: desenvolver uma compreensão integrada do meio ambiente, em suas múltiplas e complexas relações, envolvendo aspectos ecológicos, psicológicos, legais, políticos, sociais, econômicos, científicos, culturais e éticos; garantir a democratização das informações ambientais; estimular e fortalecer a consciência crítica sobre a problemática ambiental e social; incentivar à participação individual e coletiva, permanente e responsável, na preservação do equilíbrio do meio ambiente, entendendo-se a defesa da qualidade ambiental como um valor inseparável do exercício da cidadania; estimular a cooperação entre as diversas regiões do País, em níveis micro e macrorregionais, com vistas à construção de uma sociedade ambientalmente equilibrada, fundada nos princípios da liberdade, igualdade, solidariedade, democracia, justiça social, responsabilidade e sustentabilidade; fomentar a integração com a ciência e a tecnologia e da cidadania, autodeterminação dos povos e solidariedade como fundamentos para o futuro da humanidade (BRASIL, 2018).

O cumprimento desses princípios e objetivos ocorre, dentre outras formas, por meio da inserção da Educação Ambiental no currículo escolar de instituições de ensino privadas e públicas, tanto na educação básica (ensino infantil, fundamental e médio), como na educação superior, educação profissional e educação de jovens e adultos, conforme artigo 9º, da Lei 9795/99 (BRASIL, 2018).

O desenvolvimento da EA deve se dar em uma prática educativa integrada, contínua e permanente em todos os níveis e modalidades de ensino formal (artigo 10), sendo integrada às disciplinas de forma transversal, contínua e permanente (BRASIL, 2018).

Note-se que o legislador excluiu, em regra, a Educação Ambiental como disciplina específica no currículo de ensino, conforme $\S 1^{\circ}$, artigo 10 , prevendo, somente se necessário, a possibilidade de criação de disciplina em cursos de pós-graduação, extensão e em áreas voltadas ao aspecto metodológico da Educação Ambiental, segundo §2ำ, artigo 10. Também em cursos de formação e especialização técnico-profissional, em todos os níveis, deve ser incorporado conteúdo que trate da ética ambiental das atividades profissionais a serem desenvolvidas, de acordo com o §3ํㅡㄹ, artigo 10, da Lei 9795/99 (BRASIL, 2018).

A formação de professores deve ser orientada pelos princípios e objetivos da PNEA, à medida que, na forma do artigo 11, os currículos de formação de professores deverão abranger a dimensão ambiental, em todos os níveis e em todas as disciplinas, bem como à medida que professores em

revista brasileira educação ambiental 
atividades deverão receber formação complementar em suas áreas de atuação, visando a correta implementação da política em questão.

Ressalte-se que todas essas diretrizes, que dão forma à EA no âmbito formal, devem ser observadas para autorização e supervisão do funcionamento de instituições de ensino e de seus cursos, públicas ou privadas, conforme prescrito no artigo 12, da Lei 9795/99.

No que se refere às práticas educativas no âmbito não formal, tem-se que se tratam de atividades voltadas à conscientização ambiental da população, as quais buscam sensibilizá-la para questões ambientais e para a necessidade de participação ativa na defesa do meio ambiente. Para tanto, conforme dispõe o artigo 13 da PNEA, a União, o Estado e os Municípios incentivarão: a difusão, por intermédio dos meios de comunicação de massa, em espaços nobres, de programas e campanhas educativas, e de informações acerca de temas relacionados ao meio ambiente; a ampla participação da escola, da universidade e de organizações não governamentais na formulação e na execução de programas e atividades vinculadas à Educação Ambiental não formal; a participação de empresas públicas e privadas no desenvolvimento de programas de Educação Ambiental em parceria com a escola, a universidade e as organizações não governamentais; a sensibilização da sociedade para a importância das unidades de conservação; a sensibilização ambiental das populações tradicionais ligadas às unidades de conservação; a sensibilização ambiental dos agricultores; o ecoturismo.

A organização e a execução da PNEA são de responsabilidade do Órgão Gestor, no âmbito do Ministério do Estado do Meio Ambiente e da Educação, sendo que os recursos para a realização das atividades e do cumprimento dos seus objetivos serão consignados nos orçamentos dos Ministério do Meio Ambiente e da Educação e órgãos vinculados, conforme, respectivamente, artigos $2^{\circ}$ e $7^{\circ}$, do Decreto 4.281/2002.

Diante do exposto, entende-se que a Política Nacional de Educação Ambiental no Brasil está perfeitamente alinhada aos princípios e normas constitucionais e sua concretização demonstra-se essencial à formação da consciência socioambiental individual e coletiva, indispensável ao enfrentamento da crise ambiental vivenciada por todas as nações.

Não obstante, restam alguns questionamentos acerca da efetiva implementação da EA nos currículos de ensino nacional. Nesse contexto, destacando-se a Educação Ambiental no âmbito formal e sabendo que a sua concretização depende do seu desenvolvimento em todos os níveis de ensino, analisa-se, a seguir, se, e como, tem ocorrido à implementação da EA no ensino superior brasileiro, com destaque ao curso de graduação em Direito. 


\section{Educação Ambiental no Ensino Superior: análise dos ENADEs aplicados aos cursos de Direito (2006-2015)}

De acordo com o artigo 9을 da PNEA, a Educação Ambiental formal deve ser desenvolvida no âmbito dos currículos das instituições de ensino públicas e privadas, englobando a educação básica, em que se compreendem a educação infantil, o ensino fundamental e médio, a educação superior, especial, profissional e de jovens e adultos. Tal divisão é reforçada pelo artigo 21, da Lei de Diretrizes e Bases da Educação Nacional (LDBEN) (BRASIL, 1996).

Destaca-se, nesse estudo, a implementação da Educação Ambiental no ensino superior brasileiro, especificamente, nos cursos de Direito, porquanto compreende-se que "[...] da proficiência e consciência ambiental dos futuros profissionais, graduados no Ensino Superior, dependerá em parte a capacidade humana para inverter a crescente degradação do meio ambiente e instaurar a sustentabilidade planetária" (MARCOMIN, 2009, p. 104-117).

Dentre as finalidades legais da educação superior no Brasil, enfatizamse: estimular a criação cultural e o desenvolvimento do espírito científico e do pensamento reflexivo; incentivar o trabalho de pesquisa e investigação científica, visando o desenvolvimento da ciência e da tecnologia e da criação e difusão da cultura, e, desse modo, desenvolver o entendimento do homem e do meio em que vive; estimular o conhecimento dos problemas do mundo presente, em particular os nacionais e regionais, prestar serviços especializados à comunidade e estabelecer com esta uma relação de reciprocidade (BRASIL, 2018).

O Ministério da Educação (MEC) é responsável pelas funções e atribuições do poder público no âmbito da educação, sendo assistido pelo Conselho Nacional de Educação (CNE) e, especificamente em relação ao ensino superior, pela Câmara de Ensino Superior (CES), cujas atribuições estão expressamente previstas pelo artigo $5^{\circ}$ do Regimento Interno do CNE (MINISTÉRIO DA EDUCAÇÃO, 1999).

No atributo de suas competências, a Câmara de Ensino Superior (CES) institui as Diretrizes Curriculares Nacionais do Curso de Graduação em Direito, por meio da Resolução CNE/CES n. 9, de 29 de setembro de 2004. Dentre as disposições constantes da referida resolução, enfatiza-se:

Art. 3․ O curso de graduação em Direito deverá assegurar, no perfil do graduando, sólida formação geral, humanística e axiológica, capacidade de análise, domínio de conceitos e da terminologia jurídica, adequada argumentação, interpretação e valorização dos fenômenos jurídicos e sociais, aliada a uma postura reflexiva e de visão crítica que fomente a capacidade e a aptidão para a aprendizagem autônoma e dinâmica, indispensável ao exercício da Ciência do Direito, da prestação da justiça e do desenvolvimento da cidadania. 
Para tanto, a organização curricular e o seu projeto pedagógico deverão contemplar conteúdos e atividades que atendam aos eixos de formação fundamental, no qual se compreendem as relações entre o Direito e outras áreas do conhecimento, a exemplo da antropologia e da economia; eixo de formação profissional, no qual haverá o enfoque dogmático e também o conhecimento e a aplicação dos diversos ramos jurídicos, sistematicamente e contextualizados; e o eixo de formação prático, em que o aluno será levado a aplicar o conhecimento teórico na prática, conforme artigo 5을 da Resolução CNE/CES n. 09 (BRASIL, 2018).

Considerando, pois, a obrigatoriedade da Educação Ambiental no ensino superior, por força da PNEA e do Programa Internacional de Educação Ambiental, bem como pela necessidade da formação sólida, humanística e axiológica do aluno, conforme exigência expressa das Diretrizes Curriculares Nacionais do Curso de Graduação em Direito, indaga-se: a Educação Ambiental, nos cursos de Direito, é implementada de acordo com as normativas oriundas da Política Nacional e Internacional?

Para responder ao questionamento formulado, propõe-se a análise das provas do Exame Nacional de Desempenho dos Estudantes (ENADE), entendendo-se tratar de ferramenta de avaliação hábil a

[...] avaliar o desempenho dos estudantes com relação aos conteúdos programáticos previstos nas diretrizes curriculares dos cursos de graduação, o desenvolvimento de competências e habilidades necessárias ao aprofundamento da formação geral e profissional, e o nível de atualização dos estudantes com relação à realidade brasileira e mundial (INEP).

Assim, a partir da análise das provas do Enade aplicadas aos estudantes de Direito, no período trienal entre 2006-2015, pretende-se mensurar, em termos práticos, se as competências relativas à Educação Ambiental estão inseridas no ensino superior de modo transdisciplinar, conforme estabelecido pela política em contexto internacional e nacional.

De acordo com a abordagem das políticas internacional e nacional feitas anteriormente, o desenvolvimento da EA não deve se dar de modo apartado, em uma disciplina específica, mas, sim, consistir em uma prática educativa integrada, contínua e permanente. Assim, enfatiza-se, a seguir, na análise dos dados coletados, se e como as competências relacionadas à Educação Ambiental são, de modo direto ou reflexo, abordadas nas questões constantes dos Exames Nacionais de Desempenho de Estudantes.

No que tange à opção pelos cursos de Direito, vale ressaltar que a seleção justifica-se por se tratar de um curso que tradicionalmente propõe-se a preparar seus alunos para o enfrentamento de questões sociais, associado à 
compreensão dos impactos jurídicos dessas questões. Outrossim, a Educação Ambiental, como mencionado alhures, após o advento da Constituição Federal de 1988, passa a ser tratada como um direito do indivíduo, associada ao direito fundamental ao meio ambiente ecologicamente equilibrado, segundo artigo 225, da CF (BRASIL, 2018), estando intrinsecamente atrelada à educação jurídica. Como exemplo, tem-se a relação entre a Educação Ambiental e o Direito Ambiental, que apresenta, entre seus princípios estruturantes, o direito à informação, cuja garantia apresenta como condição indispensável o acesso à Educação Ambiental de qualidade (FIORILLO, 2016, p. 93-94).

A análise proposta debruça-se sobre os exames aplicados aos cursos de Direito nos anos de 2006, 2009, 2012 e 2015 - a saber, todas as provas aplicadas ao curso de Direito, desde a implementação do método avaliativo -, o que permite maior compreensão da evolução histórica recente do modo como as competências relativas à Educação Ambiental são avaliadas nesse universo específico de estudantes.

No exame aplicado em 2006 (SINAES, 2006), constata-se que não foram abordados, de modo direto ou reflexo, o tema da Educação Ambiental ou mesmo qualquer assunto dentro da seara do Direito Ambiental. Por essa razão, com a análise desse exame, não foi possível avaliar o domínio dessa competência pelos estudantes de Direito das universidades brasileiras.

Por sua vez, no exame aplicado no ano de 2009 (SINAES, 2009), havia duas questões relativas aos impactos ambientais na atualidade, ambas na seção de formação geral - questões de múltipla escolha - quais sejam, as questões 3 e 5 . A primeira delas (3) propunha a interpretação do slogan de uma campanha lançada pelo Ministério do Meio Ambiente, voltada ao incentivo do consumo consciente de sacolas plásticas. O enunciado da questão apresentava o dado alarmante de que o consumo de sacolas plásticas no Brasil havia alcançado o patamar de doze bilhões por ano, desencadeando, a partir disso, impactos para o meio urbano, o futuro e o planeta como um todo. As alternativas de múltipla escolha propostas relacionavam conceitos referentes às mudanças climáticas, ao Programa das Nações Unidas para o Meio Ambiente, ao consumo sustentável e ao padrão de produção e consumo vigentes na sociedade.

Na sequência, a Questão 5 (ENADE, 2009) abordou a relação entre desenvolvimento econômico e conservação ambiental, não raras vezes situadas em polos opostos e até mesmo conflitantes. As alternativas de múltipla escolha apresentadas abordavam algumas iniciativas e consequências que colocam em foco essa relação economia versus meio ambiente. Para interpretar e responder corretamente à questão proposta, fazia-se necessário que o estudante dominasse conceitos relativos aos impactos socioambientais dos empreendimentos $e$ atividades usualmente realizados no Brasil e compreendesse minimamente os riscos gerados por eles, de modo a avaliar e sopesar vantagens econômicas que poderiam proporcionar frente aos seus impactos negativos à natureza. 
Em termos gerais, ambas as questões abordam competências propostas pela Educação Ambiental. Na primeira (questão 3), o estudante é levado a interpretar a relação necessária entre a educação da sociedade e a viabilização de um consumo sustentável, consciente e crítico. E embora o consumo consciente seja o tema central, é inegável tratar-se de assunto integrado e essencial à compreensão dos problemas ambientais, encontrando respaldo, pois, na própria Política Nacional de Educação Ambiental (BRASIL, 2018).

No mesmo sentido, a segunda questão (5) demanda conhecimentos relativos aos impactos sociais e ambientais, desencadeados pelas ações antrópicas e é justamente essa uma das premissas sobre as quais se fundamenta o Programa Internacional de Educação Ambiental: percepção integrada do meio ambiente, por meio de processos educativos vinculados à realidade, que fundamentem ações críticas e racionais capazes de responder às necessidades sociais (UNESCO, 1977).

Vislumbra-se, portanto, da análise das questões trazidas pelo Enade 2009, que a interdisciplinaridade, a compreensão integrada do meio ambiente e suas relações fazem-se presentes e a avaliação dos estudantes quanto ao domínio das competências relativas à Educação Ambiental é concretizada.

No que se refere ao Enade aplicado no ano de 2012 (SINAES, 2012), as questões relacionadas direta ou indiretamente à Educação Ambiental situamse, em sua maioria, na seção de formação geral, sendo apresentadas na forma de múltipla escolha e abrangendo temas diversos, relativos à conservação da biodiversidade e preservação ambiental. Constatou-se, ainda, uma questão discursiva relacionada ao tema, tratando especificamente do desenvolvimento sustentável.

A Questão 2 aborda o tema da conservação da biodiversidade no cerrado, tratando, nas opções de múltipla escolha apresentadas, de práticas que incentivam ou prejudicam a preservação ambiental desse bioma, considerando as atividades comumente observadas nessas regiões. A pergunta demanda o conhecimento de aspectos ambientais e sociais específicos, relacionando a conversação dos elementos naturais às práticas regionais e às dificuldades que esses costumes impõem. Nesse passo, insta reconhecer a necessidade do domínio de competências próprias da Educação Ambiental, como a integração às diferenças regionais e nacionais, conforme artigo 4을 inciso VII, PNEA (BRASIL, 2018). Ademais, a questão coloca em foco um dos princípios basilares da PNEA, ao passo que se baseia na concepção do meio ambiente em sua totalidade, considerando a interdependência entre o meio natural, o socioeconômico e o cultural, sob o enfoque da sustentabilidade, seguindo o mesmo artigo da PNEA (BRASIL, 2018).

A seu turno, a questão 3 é construída sob a forma de interpretação de texto e trata da necessidade de engajamento de crianças e jovens na preservação ambiental, trazendo em seu núcleo conceitos relacionados, tal como a solidariedade intergeracional (SILVA, 2012). Nesse passo, a Educação Ambiental, orientada principalmente às crianças e jovens, uma vez que a 
educação enquanto processo contínuo, permanente e multidisciplinar, com foco primordial na camada jovem da população, é premissa básica das políticas nacionais e internacionais de Educação Ambiental, conforme artigo 4ํㅜㅇ inciso $\mathrm{V}$ e artigo 5으, inciso IV e VII (BRASIL, 2018).

A Questão 7 do Exame (2012), igualmente elaborada sob a forma de interpretação de texto, relaciona-se aos compromissos ambientais globais assumidos por parlamentares de diversos países do mundo na Conferência Rio+20. Entre outros temas, as alternativas propostas versam sobre a força legal interna dos compromissos, o grau de comprometimento dos países com questões ambientais e as atitudes adotadas no plano internacional quanto ao impacto das mudanças climáticas.

$\mathrm{Na}$ questão discursiva (1), o aluno é chamado a discorrer sobre a relação conflitante entre o incentivo fiscal à compra de veículos automotores e o desenvolvimento sustentável, abrangendo em sua resposta possíveis ações para o fomento do transporte urbano sustentável.

A proposta de redação tem por escopo fomentar o pensamento crítico quanto à sustentabilidade dos meios de transporte urbano, relacionando-se sobremaneira à PNEA e às premissas do Programa Internacional de Educação Ambiental, uma vez que avalia as aptidões dos estudantes quanto à percepção integrada do meio ambiente, avaliando sua capacidade de raciocínio e articulação lógica no que tange às ações críticas capazes de responder às demandas socioambientais da atualidade.

Por fim, da análise da última prova aplicada, a saber, no ano de 2015 (SINAES, 2015), verificam-se questões relacionadas à responsabilidade social corporativa, ao direito ambiental e ao direito fundamental ao meio ambiente equilibrado, todas elas essenciais para a compreensão do tema.

A questão 3 do Exame, inserida na seção de formação geral, foi formulada com base no padrão de múltipla escolha e propõe a interpretação de um gráfico referente à responsabilidade social corporativa, incluindo-se, nesse campo, a responsabilidade da empresa no que se refere às adversidades ambientais. As alternativas de múltipla escolha apresentadas referem-se ao impacto dos fatores ambientais no sucesso ou no fracasso de atividades empresariais e no papel desempenhado pelas boas práticas ambientais no acesso, pelas empresas, a linhas de financiamento.

A pergunta coloca em foco a importância da compreensão integral dos impactos ambientais para o processo decisório e gestão de riscos empresariais, destacando, ainda de modo indireto, o papel essencial da Educação Ambiental para o enfrentamento de questões cotidianas e para a construção do pensamento crítico. Nesse passo, coloca em prática o estímulo e o fortalecimento à consciência crítica sobre a problemática ambiental e social, objetivo que deve orientar as ações em Educação Ambiental, conforme orienta a PNEA. 
De seu turno, na questão 29 (ENADE, 2015), o direito ambiental e o direito administrativo são relacionados ao questionamento do aluno quanto à legalidade de uma construção em área de proteção ambiental. Para acertar a pergunta, é essencial que o estudante domine o texto constitucional, em especial no que se refere ao compromisso imposto ao Poder Público quanto à proteção do meio ambiente, no seu sentido amplo, compromisso este estendido a toda a coletividade, conforme artigo 225, da CF. Propõe-se averiguar o grau de conhecimento do aluno em torno do direito ambiental, especialmente em relação ao sistema nacional de unidade de conservação da natureza.

Por fim, a questão 30 do Exame versa sobre o direito fundamental ao meio ambiente equilibrado e a possibilidade de ajuizamento de ação popular para a defesa e garantia desse direito. A indagação aborda o conceito de meio ambiente a partir de quatro critérios distintos e concebe a existência de ambientes natural, artificial, cultural e laboral. Ademais, o enunciado atribui a preservação ambiental ao Poder Público e a toda a coletividade e destaca, sobretudo ao estudante submetido à avaliação, seu papel enquanto ser social encarregado da defesa e da preservação do meio ambiente.

Em termos gerais, portanto, constata-se que os exames de Enade aplicados aos cursos de Direito, nos anos de 2006, 2009, 2012 e 2015, buscam avaliar, ainda que de modo reflexo, o nível de domínio dos estudantes quanto às habilidades e aos conhecimentos relativos às problemáticas ambientais vivenciadas em todo o mundo. Além disso, verifica-se que em consonância com o que preconizam os princípios norteadores da PNEA, as questões são, de modo geral, estruturadas segundo uma perspectiva ampla e adotam uma concepção holística de meio ambiente, considerando a interdependência entre o meio natural, o socioeconômico e o cultural.

Os objetivos da PNEA também estão contemplados nas questões analisadas, tendo em vista que, de modo geral, elas se direcionam à solução de problemas socioambientais a partir de uma consciência crítica, destacando, em muitas passagens, o papel social dos indivíduos na preservação do meio ambiente.

Com base na análise realizada, portanto, é possível compreender que a implementação da Educação Ambiental nos currículos dos cursos de Direito no Brasil ocorre em observância aos princípios e aos objetivos constantes da PNEA, bem como às orientações internacionais, sendo que o domínio das competências tem sido, de fato, verificado pelos órgãos de ensino responsável pela avaliação dos cursos superiores nacionais. 


\section{Considerações finais}

Desde 1968, com a Criação do Conselho para Educação Ambiental, no Reino Unido, a comunidade internacional vislumbra, na Educação Ambiental, um importante instrumento para o enfrentamento dos elementos que constituem e agravam a crise ambiental em todo o mundo. Diversos eventos pró-ambientalistas, na sequência, chamaram a atenção dos Estados para a importância da implementação de práticas educativas, a exemplo da Conferência das Nações Unidas, realizada no ano de 1972, em Estocolmo; do primeiro Encontro Internacional em Educação Ambiental, ocorrido em 1985, em Belgrado, na lugoslávia; da Conferência Intergovernamental de Educação Ambiental de Tbilisi, organizada pela Unesco, em 1987, na cidade de Moscou, na Rússia; e da II Conferência das Nações Unidas sobre Meio Ambiente e Desenvolvimento, realizada no Rio de Janeiro, em 1992.

Como fruto desses movimentos em defesa do meio ambiente, tem-se o Programa Internacional de Educação Ambiental, que se estrutura na implementação da EA, enquanto processo contínuo, permanente e multidisciplinar, tanto no âmbito da educação formal como não formal. Buscase, por meio da interdisciplinaridade e da revisão dos métodos tradicionais de ensino, ensinar uma concepção holística socioambiental, educando o cidadão para a percepção integrada do meio ambiente, com vistas a fundamentar ações críticas e racionais.

Fundamentada nas diretrizes internacionais, a EA ganha espaço na legislação brasileira a partir da década de 80 , após a instituição da Política Nacional do Meio Ambiente (Lei n. 6.938/71), que positiva, dentre seus princípios norteadores, a Educação Ambiental em todos os níveis de ensino, inclusive a educação da comunidade, com o objetivo de capacitá-la para participação na defesa do meio ambiente (BRASIL, 2018).

Sabe-se que, nesse período, a Educação Ambiental no Brasil encontra forte resistência em razão dos inúmeros outros problemas sociais e políticos enfrentados, à época, pela sociedade. De fato, a questão ambiental era vista como uma "ideologia importada" que buscava desviar a atenção daquilo se consideravam problemas reais (baixo nível de escolaridade da população, miséria, fome, etc.). Somado a isso, tem-se a instalação do regime ditatorial, no qual foram reprimidas todas as liberdades individuais, dificultando, pois, sobremaneira, a formação de uma consciência ambiental.

A Educação Ambiental somente ganha contornos de efetividade após o advento da Constituição Federal de 1988, quando é reconhecida como um direito fundamental do indivíduo, por força do artigo 225, inciso $\mathrm{VI}$, sendo o Poder Público responsável pela sua promoção em todos os níveis de ensino e a conscientização pública para a preservação do meio ambiente, tudo em prol da preservação do equilíbrio ambiental, essencial à sadia qualidade de vida dos seres vivos. 
Visando dar efetividade ao dispositivo constitucional, em 27 de abril 1995, por meio da Lei n. 9.795, entra em vigor no ordenamento jurídico brasileiro a Política Nacional de Educação Ambiental (PNEA), posteriormente regulamentada pelo Decreto n. 4.281/2002.

A partir da análise da PNEA, compreende-se a inserção da EA enquanto processo de construção de valores indispensáveis à preservação ambiental e componente essencial e permanente da educação nacional, em todos os níveis e modalidades de ensino formal e informal.

Verifica-se, outrossim, que todos os agentes sociais e políticos têm o dever de promover o desenvolvimento da EA, sempre em observância aos princípios e objetivos da PNEA, previstos especificamente pelos artigos $4^{\circ}$ e $5^{\circ}$ da referida política. Tais princípios e objetivos, inclusive, são analisados para autorização e supervisão do funcionamento de instituições de ensino e seus cursos, públicas ou privadas.

No âmbito da educação formal, objeto específico do trabalho, tem-se que a EA deve ser implementada no currículo escolar de instituições de ensino privadas e públicas, tanto na educação básica (ensino infantil, fundamental e médio), como na educação superior, educação profissional e educação de jovens e adultos, em uma prática educativa integrada, contínua e permanente, sendo integrada às disciplinas de forma transversal. Frise-se, portanto, que não haverá para a Educação Ambiental uma disciplina específica nos currículos nacionais, com exceção em casos necessários de cursos de pós-graduação, extensão e em áreas voltadas ao aspecto metodológico da Educação Ambiental.

Denota-se, a partir da análise da PNEA, que as diretrizes se encontram em consonância aos princípios e normas constitucionais, bem como às orientações internacionais relativas à EA. A efetiva implementação desse instrumento jurídico de defesa ambiental, com a formação da consciência socioambiental individual e coletiva, apresenta-se essencial ao enfrentamento da crise ambiental.

Com efeito, o estudo apresenta uma análise da implementação da EA no ensino superior brasileiro, especificamente, nos cursos de graduação em Direito. A escolha do curso fora feita com base na necessidade de formação de juristas aptos à compreensão e ao enfrentamento dos impactos jurídicos e sociais decorrentes dos problemas ambientais vivenciados pela humanidade.

Em análise das Diretrizes Curriculares Nacionais do Curso de Graduação em Direito vigentes desde 2004, constata-se que a referida graduação deverá assegurar ao aluno, dentre outras questões específicas correlatas à profissão jurídica, uma formação geral sólida, humanística e axiológica.

Nesse contexto e considerando a obrigatoriedade do ensino da EA em todos os níveis de ensino, a fim de avaliar se a Educação Ambiental, nos cursos de Direito, é implementada de acordo com as normativas das políticas 
nacional e internacional de Educação Ambiental, realizou-se uma análise das provas do Exame Nacional de Desempenho dos Estudantes (ENADE), qual seja, um método avaliativo que tem por objetivo avaliar o ensino superior no Brasil, em relação aos conteúdos programáticos dos cursos, competências e habilidades dos graduandos.

Foram analisadas todas as provas aplicadas aos cursos de Direito no Brasil, quais sejam, os exames de 2006, 2009, 2012 e 2015, constatando-se, em síntese:

a) no exame de 2006, a inexistência de questões com abrangência da temática ambiental;

b) no exame de 2009 , duas questões (3 e 5) relativas aos impactos ambientais na atualidade, ambas na seção de formação geral, cujo assunto principal referia-se, respectivamente, aos padrões de produção e consumo vigentes na sociedade contemporânea e à relação conflituosa entre desenvolvimento econômico e conservação ambiental;

c) no exame de 2012, quatro questões (duas na modalidade múltipla escolha e uma na modalidade discursiva, todas elas no eixo de formação geral) abrangendo aspectos ambientais e sociais específicos (p.ex. conversação dos elementos naturais relacionados às práticas regionais), a necessidade de engajamento de crianças e jovens na preservação ambiental, os compromissos ambientais globais assumidos por parlamentares de diversos países do mundo na Conferência Rio+20 e a problemática da relação entre crescimento econômico e desenvolvimento sustentável;

d) no exame de 2015, três questões (uma questão no eixo de formação geral e duas em formação específica) avaliam conteúdos relacionados à responsabilidade social corporativa, incluindo-se a responsabilidade ambiental, ao direito ambiental em geral, com ênfase às áreas de proteção ambiental, e ao direito fundamental ao meio ambiente equilibrado e a tutela judicial deste bem jurídico.

De forma geral, das análises feitas aos ENADEs aplicados aos cursos de Direito, em todo o Brasil, no período trienal 2006-2015, pode-se concluir que os alunos têm sido avaliados em relação ao domínio de habilidades interpretativas a temas diversos relacionados à preservação ambiental, de forma que se permite admitir que as diretrizes curriculares estão sendo construídas de modo a fornecer ao aluno uma concepção holística de meio ambiente, bem como à capacidade de desenvolver uma consciência crítica, em observância, portanto, aos princípios e objetivos da PNEA, assim como às diretrizes internacionais pertinentes ao tema. 


\section{Referências}

BRASIL. Constituição Federal de 1988. Diário Oficial, Brasília, 1981. Disponível em: <http://www.planalto.gov.br/ccivil 03/constituicao/constituicao compilado.htm>. Acesso em: 18 jan. 2018.

BRASIL. Decreto n. 4.281 de 25 de junho de 2002. Diário Oficial, Brasília, 2002. Disponível em: <http://www.planalto.gov.br/ccivil 03/decreto/2002 /d4281.htm>. Acesso em: 18 jan. 2018.

BRASIL. Lei n. 6.938 de 31 de agosto de 1981. Diário Oficial, Brasília, 1981. Disponível em: <http://www.planalto.gov.br/ccivil 03/leis/L6938.htm>. Acesso em 18 jan. 2018.

BRASIL. Lei n. 9.394 de 20 de dezembro de 1996. Diário Oficial, Brasília, 1996. Disponível em: <http://www.planalto.gov.br/Ccivil 03/leis/L9394.htm>. Acesso em 08 fev. 2018.

BRASIL. Lei n. 9.795 de 27 de abril de 1999. Diário Oficial, Brasília, 1999. Disponível em: <http://www.planalto.gov.br/ccivil 03/leis/19795.htm>. Acesso em: 18 jan. 2018.

DIAS, G. F. Educação Ambiental: princípios e práticas. São Paulo: Gaia, 2000.

FIORILLO, C. A. P. Curso de direito ambiental brasileiro. 17. ed. São Paulo: Saraiva, 2016.

INSTITUTO NACIONAL DE ESTUDOS E PESQUISAS EDUCACIONAIS ANÍSIO TEIXEIRA (INEP). Enade. Disponível em: $<$ http://portal.inep.gov.br/enade?>. Acesso em: 10 fev. 2018.

LIMA, G. F. C. Educação Ambiental no Brasil: formação, identidades e desafios. Campinas, SP: Papirus, 2015. Recurso eletrônico.

LUZZI, D. Educação e meio ambiente uma relação intrínseca. São Paulo: Manole, 2012. Recurso on-line.

MARCOMIN, F. E.; SILVA, A. D. V.. A sustentabilidade no ensino superior brasileiro: alguns elementos a partir da prática de Educação Ambiental na Universidade. Contrapontos, v. 9, n. 2, p. 104-117, Itajaí, maio/ago. 2009.

MINISTÉRIO DA EDUCAÇÃO. Regimento interno do Conselho Nacional de Educação, instituído pela Portaria MEC № 1.306, de 02 set. 1999. Disponível em: <http://portal.mec.gov.br/index.php?option=com docman\&view=download \&alias=1529-regimento-interno-cne-1\&category slug=documentos-pdf\&ltemid= 30192>. Acesso em: 09 fev. 2018.

MINISTÉRIO DA EDUCAÇÃO. Um pouco da História da Educação Ambiental. Disponível em: <http://portal.mec.gov.br/secad/arquivos/pdf/ educacaoambiental/historia.pdf >. Acesso em: 06 jan. 2018b. 
MINISTÉRIO DA EDUCAÇÃO; SECRETARIA DE EDUCAÇÃO FUNDAMENTAL. Políticas de melhoria da qualidade da educação: um balanço institucional. Disponível em: <http://portal.mec.gov.br/seb/arquivos/pdf/Relat.pdf>. Acesso em: 06 jan. 2018. MINISTÉRIO DA EDUCAÇÃO. Carta de Belgrado. lugoslávia, 1975. Disponível em: <http://www.mma.gov.br/informma/item/8066-carta-debelgrado>. Acesso em: 12 dez. 2017.

MINISTÉRIO DO MEIO AMBIENTE. Carta de Belgrado. lugoslávia, 1975. Disponível em: <http://www.mma.gov.br/informma/item/8066-carta-debelgrado>. Acesso em: 12 dez. 2017.

PHILIPPI JUNIOR, A.; PELICIONI, M. C. F. Bases políticas, conceituais, filosóficas e ideológicas da Educação Ambiental. In: PHILIPPI JUNIOR, A.; PELICIONI, M. C. F. Educação Ambiental e sustentabilidade. 2.ed. rev. e atual. Barueri, SP: Manole, 2014.

SILVA, M. V. O princípio da solidariedade intergeracional: um olhar do Direito para o futuro. Veredas do Direito: Direito ambiental e desenvolvimento sustentável, Belo Horizonte, v. 8, n. 16, abr. 2012, p. 119-121. Disponível em: $<$ http://domhelder.edu.br/revista/index.php/veredas/article/view/179>. Acesso em: 12 dez. 2017.

SINAES. Exame Nacional de Desempenho dos Estudantes. Direito. 2006. Disponível: $\quad<$ http://download.inep.gov.br/download/enade/2006/Provas/ PROVA DE DIREITO.pdf>. Acesso em: 05 jan. 2018.

SINAES. Exame Nacional de Desempenho dos Estudantes. Direito. 2009. Disponível em: <http://public.inep.gov.br/enade2009/DIREITO.pdf >. Acesso em: 05 jan. 2018.

SINAES. Exame Nacional de Desempenho dos Estudantes. Direito. 2012. Disponível em: <http://download.inep.gov.br/educacao superior/enade/provas/ 2012/07 DIREITO.pdf>. Acesso em: 05 jan. 2018.

SINAES. Exame Nacional de Desempenho dos Estudantes. Direito. 2015. Disponível em: <http://download.inep.gov.br/educacao superior/enade/provas/ 2015/08 direito.pdf>. Acesso em: 05 jan. 2018.

TOZONI-REIS, M. F. de C.. Formação dos educadores ambientais e paradigmas em transição. Ciência \& Educação (UNESP), São Paulo, v. 8, p. 84, 2002. Disponível em: <http://www.scielo.br/scielo.php?script=sci arttext \&pid=S1516-73132002000100007>. Acesso em: 12 dez. 2017.

UNESCO. Declaração da Conferência Intergovernamental sobre Educação Ambiental. Tbilisi, Geórgia (antiga URSS). Out./1977. Disponível em: $<$ http://igeologico.sp.gov.br/wp-content/uploads/cea/Tbilisicompleto.pdf>.

Acesso em: 12 dez. 2017. 